\title{
Adoption of Energy Efficient New Technologies from the Point of View of Malaysian Experts and Consumers: A Qualitative Analysis
}

\author{
Hasti Khorasanizadeh, Jussi Parkkinen, and Rajendran Parthiban
}

\begin{abstract}
This paper presents the result from interviews about consumers' reasons for adopting or not adopting energy-efficient technologies, specifically LED lamps, in Malaysia. Data were gathered via 18 in-depth semi-structured interviews. The interviewees were chosen from two groups: energy and environment professionals and normal electricity consumers. The respondents were mainly environmentally concerned. They believed that typical reasons, which could encourage consumers to adopt new technologies, are energy efficiency, money savings or environmental conciousness. It was also concluded by this study that consumers might not favor adopting new technologies due to price barriers, lack of knowledge and not effective policies.
\end{abstract}

Index Terms-Energy efficiency, low carbon technologies, LED, Malaysia, sustainability.

\section{INTRODUCTION}

Interest in energy efficiency improvements has been reinvigorated by concerns about environmental effects of fossil fuels depletions, air pollution as a fact of combusting fossil fuels, climate change and environmental damages, energy price and national security. Improving energy efficiency is seen as one of the most relevant measures to reduce $\mathrm{CO}_{2}$ emissions, and a fast and cost effective way to improve security of energy supply [1].

There are many studies mostly in Europe on the factors influencing consumer adoption of energy efficiency [2]-[4]. In Malaysia also, government has identified sustainable development as a national priority in its $9^{\text {th }}(2006-2010)$ [5] and $10^{\text {th }}(2011-2015)$ [6] Malaysia Development Plans. Malaysia's $11^{\text {th }}$ plan (2016-2020), is working to make green technology the preferred choice in obtaining products and services [7]. As for, recent government policies, such as "National Green Technology Policy" and "National Policy on Climate Change", are promoting energy-efficiency technologies among energy consumers, provide assistance for Malaysia to reach its plans.

Malaysia's electricity energy consumption grew at $23 \%$, increasing from 1.8 Mtoe in 1990 to 10.5 Mtoe in 2011 [8]. The Malaysian energy mix relies predominantly on fossil fuels with oil as the main source of supply until it was gradually replaced by gas, following the introduction of the Fourth Fuel Diversification Strategy in 1981 [9].

Manuscript received April 5, 2014; revised June 18, 2014.

H. Khorasanizadeh, J. Parkkinen, and R. Parthiban are with the Discipline of Electrical and Computer Systems, School of Engineering, Monash University Malaysia Campus, Jalan Lagoon Selatan, 47500 Bandar Sunway Selangor Darul Ehsan, Malaysia (e-mail: \{hasti.khorasanizadeh, jussi, rajendran.parthiban\}@monash.edu).
Fig. 1 shows Malaysia's electricity generation from 1990 to 2011 by different primary sources. In recent years, a further transition from gas to coal took place, driven primarily by a governmental policy that favors the use of coal for electricity generation [10]. That causes $\mathrm{CO}_{2}$ emission increase from $49.64 \mathrm{Mt}$ of $\mathrm{CO}_{2}$ in 1990 to $193.96 \mathrm{Mt}$ of $\mathrm{CO}_{2}$ in 2011 [8]. Fig. 2 shows the relation between energy use and $\mathrm{CO}_{2}$ emission in Malaysia. This graph clearly shows the increase in the distance of these trends highlighting the more usage of coal in the recent years leading to higher amount of emissions.

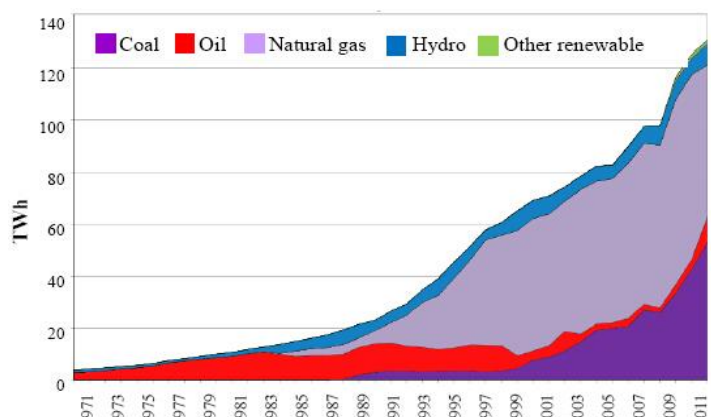

Fig. 1. Malaysia's electricity generation by fuel [8]

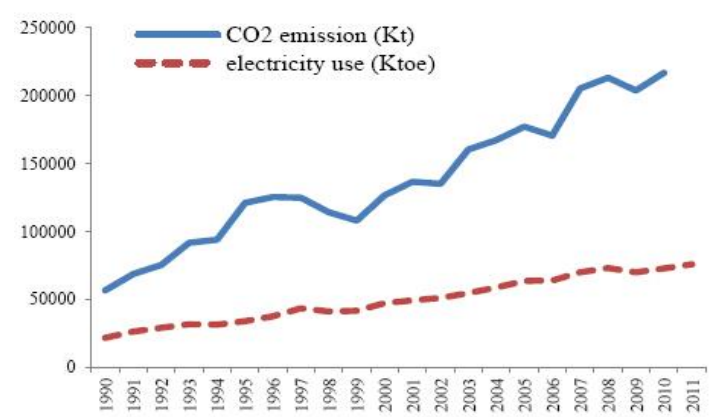

Fig. 2. Relation between energy use and $\mathrm{CO}_{2}$ emission [11].

US Department of Energy, in their report [12] concluded that a consumer switch to more energy efficient technologies could achieve a substantial reduction in energy use and environmental emissions. A good example to this change is the conversion of lamps in the households to more energy saving lamps such as LEDs.

Since the green revolution is mainly consumer driven, people's environmental knowledge is of dominant significance. This suggests that if consumers have a higher understanding of environmental issues and are able to relate it to ecologically conscious consumption behaviors, the concept of green marketing is strongly encouraged. This encouragement is expected to be fulfilled through benefit-driven creativities. Consumer knowledge about 
ecological issues has been known as a substantial predictor for environmentally friendly behaviors [13]. However, contrasting to knowledge and behavior, attitudes are the most important predictors of consumers' willingness to pay more for environmental friendly products. It has been reported that two attitudes namely importance and inconvenience have been studied most by researchers [14]. Amyx et al. [15] have described the term "importance", with respect to the environment, as the degree to which one expresses concern about ecological issues. This simply means that importance is if consumers value environmentally compatible behaviors as an important fact to themselves or the entire society. The term "Inconvenience" refers to how problematic it is for the consumer to follow an ecologically favorable behaviour [14]. In a simpler way is the consumer avoiding to behave environmental friendly in a condition, which he/she is aware of the importance due to inconvenience caused. Since different cultures can show different attitudes and behaviors in adopting environmental technologies, the solution to encourage that community will not necessarily be the same. Malaysia is for sure not an instance. So far based on the knowledge of the authors there has been no survey on this issue carried out in Malaysia. Since Malaysia is a developing country, which makes the growth in use of energy to have a high rate, this study is of great importance.

This paper surveyed the factors influencing Malaysian's adoption and resistance towards adoption of green technologies. The main target of this study is on energy efficient lighting technology adoption in Malaysia. Previous researches in other regions have shown that lack of information, high upfront costs, lack of reliable brands and long payback time are the different barriers to improve energy efficiency [3]. On the other hand, social approval, divisibility, relative advantages, compatibility to the existing system and save in maintenance costs are the factors that perceived by the potential adopters [16]. Anderson and Newell [17] in their research found that adoption rates are higher for projects with shorter payback, lower costs, greater annual saving, higher energy price and greater energy conservation.

This study is part of a three-year project to design an educational model for Malaysians to adopt energy efficient LED lights. The study reported in this paper explored Malaysian attitudes and knowledge toward energy saving and green technology. This research is a primary step to an online questionnaire design for factors of LED adoption in Malaysia.

\section{Methodology}

This study is an exploratory study, which involves 9 pilot interviews with experts in energy and environment and 9 interviews with normal electricity consumers. Interviews were conducted between January and March 2013. The length of the interviews varied between 16 min to $41 \mathrm{~min}$ in a semi-structured design allowing participants to express their particular views. A literature review in this topic was carried out to discuss the results of the interviews. Based on arguments posted by Strauss and Corbin [18], a theoretical framework was setup through the literature review and subsequently interview questions were designed accordingly.
In this research phase, the questions were divided into three themes: In theme one, the aim was to explore the characteristic of green technology. In the second theme the focus was given on knowledge of participants about energy efficient lights such as LED; and finally in the last theme the interviewees were asked about the changes that should be made to publicize energy efficiency technologies. TABLE I shows the outlines and themes for the interviews. This data were used to identify the main factors influencing adoption of energy efficiency and low carbon lighting technologies among Malaysian consumers. These data are essential as a platform for the next levels of this research, which is the relation between consumer's behavior and knowledge in using energy efficient lights.

The interviews were audio-recorded and transcribed strictly. They were then coded using the NVivo software package and subsequently analyzed inductively to draw out themes. The findings presented in the next section arise from this analysis.

TABLE I: SUMMARY OF THEMES AND OUTLINES

\begin{tabular}{|c|c|}
\hline Themes & Outline of questions \\
\hline $\begin{array}{l}\text { Characteristic of green } \\
\text { technology }\end{array}$ & - the characteristics of green products \\
\hline $\begin{array}{l}\text { Knowledge, attitude and } \\
\text { behavior for energy } \\
\text { efficiency and led }\end{array}$ & $\begin{array}{l}\text { - type of information about energy } \\
\text { efficient lighting } \\
\text { - risks associated with saving and not } \\
\text { saving electricity } \\
\text { - relation between people's attitude } \\
\text { and action in electricity saving } \\
\text { - effects of light in people's well being }\end{array}$ \\
\hline $\begin{array}{l}\text { Recommendations to } \\
\text { apply energy efficiency } \\
\text { and LED }\end{array}$ & $\begin{array}{l}\text { - Changes for lighting systems } \\
\text { - Communication sources } \\
\text { - Specific opinion about implementing } \\
\text { and improving its use in Malaysia }\end{array}$ \\
\hline
\end{tabular}

\section{FINDINGS AND DISCUSSION}

The findings from the interviews are presented below in different sections under themes mentioned above. Wherever applicable, descriptive quotes are taken from the interview transcripts and have been inserted to express the viewpoints of the interview participants.

\section{A. Characteristics of Green Technology}

Recently there has been a growing interest in introducing environmental, health and safety consideration to achieve sustainable products. Green technology is developed and used in a way that protects the environment and conserves natural resources. A part of the renewable energy branch of the environmental technology movement, the green technology importance cannot be ignored. It has been recognize that the characteristics of the green technology can affect in environment and pollution.

Four pillars of green technology policy pointed out by Malaysian Government are [9]:

- Energy - This pillar aims to obtain energy independence and publicize efficient applications;

- Environment - Looking into environment will help the community to save and reduce the effects on the environment;

- Economy - This pillar can improve the national economic development with the aid of new and green 
technology;

- Social - This Pillar Increases the quality of life for everyone.

Combining participants' opinion in this study (both expert and non-expert interviews) on characteristics of green technology led to a definition. The participants generally defined green technology as the product, equipment or systems, which are used to protect the earth and natural resources. These technologies reduce and limit the harmful effects of human beings' behavior on earth. Based on the interviews, the findings reveal that Green Technology represents products, which fulfill the following requirements:

- Reduces the degradation of the environment;

- Possesses minimal greenhouse gas (GHG) emission and makes environment better for any varieties of life;

- Conserves the consumption of energy and natural resources;

- Encourages the application of renewable sources.

"It should be sustainable, it should have sustainable renewable source, and it should have very small foot print in terms of waste and environmental impact. That's for make it green." (Expert interviewee).

"Low energy uses, long lasting, low carbon footprint." (Non-expert interviewee).

It is necessary to link the findings from the point of view of consumers and professionals to the government policies. This is mainly important because a huge burden in saving the environment and also benefits of better life is on the consumers directly. Looking into the first observation of adopting green technologies from the point of view of interviewees it can be noted that this finding is in direction with the Environmental Pillar as defined by Malaysian government policy. This helps to have a more sustainable environment. Also the second finding on reduction of GHG emissions helps to have a better environment. Besides that reduction in GHGs can prevent midpoint categories such as global warming and ozone depletion as a midpoint category and correspondingly less harm to human being health. Conserving the consumption of energy can directly affect the economy of the consumers. Also easier sustainability in natural resources could be achieved. As an example the time required for a forest to be replaced will no longer be an issue. The energy independence based on available resources could be achieved as well which addresses the Energy Pillar of Malaysian Government Policy. The use of renewable resources can help almost all of the pillars mention in the policy above. In terms of energy the independence will be more sustainable as non-renewable resources are depleting sooner or later. Environmentally renewable resources are potentially less harmful to the environment as resources could be reused for several times. Economic wise new material could provide areas of income and job opportunities. More jobs can enhance the quality of life and also a sustainable use of resources for the future generation. As a conclusion to this section both consumers and professionals have a good understanding towards the characteristics of green technology. However, this does not make them to adapt to new technologies as per mentioned earlier.

\section{B. Knowledge, Attitude and Behavior}

The most useful information, that participants named for energy-efficient lights, were price, reliability, quality, performance and payback time of the product. This is an argument with Caired et al. [3], Even though the concerns might be the same, but the way of looking into these parameters in different cultures might not be the same and further investigation is required. It was mentioned by the participants that this information should be contextualized so it is related to their everyday lives and situations. It was suggested that information is valuable when they can compare the energy-efficient light with other similar products that they widely use. Participants argued that information should be true, relevant and useful to have good influence on the costumers.

"I think maybe if there was something that could tell people exactly how much energy, in money terms, they wasted on certain things that might actually work better" (Non-expert interviewee).

This quote by a non-expert consumer reveals the importance of tangible information on a given product. This information is not necessarily technical and probably economic concerns should be more addressed. The expert interviewees argued that the information should be new for consumers and meanwhile specific.

"We should drive the idea that LEDs are safe and environmental-friendly. They offer cost savings. LEDs can enable thin, compact lighting units for better styling in all sorts of applications. The saturated colors can give a higher-value appearance. Stable light output even with voltage fluctuations." (Expert Interviewee).

Information relating to level of consumption, performance and quality needs to be articulated in a language that attaches every day structures of consumers' life. However, centering on money saving is found as a helpful, specific and probably temporary way of motivating more sustainable lifestyles [19].

This study's data discovered a week relation between attitudes on the electricity saving and electricity saving behavior. As literature [20], [21] also confirms, expert interviews noted that routine consumption between public is controlled by social norms and is shaped by culture and economic. It was made clear during non-experts' interviews that financial achievements were preferred than environmental achievements. Though, expert interviewees mentioned that economic development and environmental protection are inseparable and should look at them simultaneously. Previous study in the field of electricity saving [22] included that, psychological variables are possibly helpful in trying to clarify pro-environmental behavior. Social value orientation, psychological barriers to energy conservation, and intrinsic motivators are probably effects on pro-environmental behavior [22].

"But anyway whom which aware of environmental problems, have more understanding about saving energy and electricity but not necessarily act in the same way." (Expert interviewee). 
This comment is highlighting the fact that knowledge on environment does not grantee an environmental friendly behavior. This could be due to the attitudes such as importance and inconvenience [14]. As outlined by Bernstroem [23], risk understanding might possibly be significant in awareness of electricity saving. Risk perception study has addressed the ways people often view the risks in their surroundings as well as risks arising from various energy sources. Non-expert interviewees mentioned waste of money and energy sources as risks associated in not saving electricity. The expert participants added a consideration for the environment; consideration for next generations; consideration for wellbeing issues to above risks.

"By saving electricity we can also save bill costs and also reduce tax for public lighting, we also can reduce $\mathrm{CO}_{2}$ emissions and also reduce the electronic wastes." (Non-expert interviewee).

Both interviewees agreed that light has effect on people's mood. Expert interviewees explained how possibly light can have effect on people's wellbeing. As can be noted in the quote below by an expert interviewee, proper lightening not only can affect the mood but also it is important due to safety aspects. There are a lot more examples that light and quality of light can affect the wellbeing of human light.

"There is a huge amount of studies about light effects on people, psychologically and physiologically as well. Some of them are on work safety, it's not only the amount of light also quality of light. For example people working with heavy machinery in large rooms, how can you light up specific areas for safety. For example people don't fall asleep while working and conditions people more or less aware when working. "(Expert interviewee).

Another aspect of lighting, which should be considered in wellbeing, is the fact that different occasions might require different quality and color of light. Wrong selection of light color not only can affect the mood, but also can increase unnecessary usage of light. As an example dim light in restaurants can bring more relaxing moments for the costumer. Besides that using dim lights can reduce the energy usage as less powerful lamps could be used.

"Light can have effect on the social life, if you feel relax under a certain light you have a better mood and this can increase the social life. It also have effect on physical and mental wellbeing, different light colors are used for different occasions." (Non-expert interviewee).

These quotes from the interviews reveal the importance of proper lighting in the aspect of quality and color of lighting. The following quote has been also confirmed by other researches on lighting quality [24]-[26]. These studies revealed that lighting in an environment is one of the essential elements that have direct influence on people's performance and mood.

"There are many studies about how people see colors in different lights. There are lots of information about aspects of light in psychology and the effect of light in people's mood.
Physiologically if people don't get light they become depressed and sick."(Expert interviewee).

As a conclusion to this section, it is understood that in order to encourage people to adopt a new technology aspects regarding wellbeing and health should also be considered beside the costs associated with that technology.

\section{Recommendations}

For the majority of our non-expert attendees, it was essential that the information given is from a trustworthy resource. They highlighted that they don't completely trust advertisements by manufactures; because they only provide information they want consumers to know. They prefer the information about energy-efficiency to be confirmed or given from technicians or professionals.

Chapman and Sharma [27], discovered in their research that often, young people receive environmental tips mostly from television, periodical and newsprint; and also their families are considering a comparatively weak provider. Findings from our interviews show that learning from social networks is very common nowadays, as internet is widely used by people especially youth. People hear the experiences of their peers who use these technologies on energy-efficient weblogs and through internet, by means of this information sharing awareness for positive action raise. All the interviewees agree that graphical advertisements have more effect on public.

"People are busy to read the advertisements and if the image grabs them they will read the whole thing." (Non-expert interviewee).

However, advertisement via telephone, email or being stopped by advertisers in public areas doesn't have much effect. This is probably due to the fact that these advertisers are not considered trustworthy by the consumers. There is a point here that consumers could trust information on the internet or from their peers in social networks; however, trusting the advertising people is much less as compared. The contradiction is that their peers are not necessarily professionals and not all the information on the net is trustworthy. This could be contradictory situation is attributed to the fact that advertisers are financially benefiting from promoting that product. Whereby there are no visible benefits for the peers on social network or information on the net. Expert interviewees suggested starting raising people awareness from early ages, because children carry energysaving messages home to their family. They suggest educating students on energy efficiency and environment in schools and universities. They mentioned that teachers could be the source of information and books could also mention environmental tips occasionally. For example, with in science lessons, students get knowledge about different types of energy source, how electricity is produce and their environmental effects. Besides that when something is thought to the children from early age it is like being engraved in their mind. This will be carried forward to the next generation.

"Children are very easily gaining the information and they can transfer this information inside the family, so training in 
the schools as well as in the higher education might be effective." (Expert interviewee).

Besides those, educating adults is not of less importance as compared to the children. Part of the adult education can be in a passive way through the teachings to their children. Other educating ways imposed by government, government bodies or Non-Governmental Organizations (NGOs) could be through TV shows with no financial benefits for the producers. Banners and informative graphics in the cities without promoting any specific product could also be a reliable source for people to get educated.

"It is really big point in terms of educating the Malaysian public because people are not very keen to electricity to switch on and off, they have no idea where is it comes from, they have no idea what is involved in generating electricity. The electricity pulls is in form of linear but in order for us to use it we need some generator we have to spend some sort of mechanical energy to turn it to electricity and most people don't understand that stuff. I think if people understood that the electricity here is generated by fossil fuel, and they understand that fossil fuels are polluting and limited in resource then they start to appreciate why it is important to save electricity. People need basic understanding. For electricity the critical thing is renewable source and energy efficient technologies. The abstract idea is people have to have the quit bit of education for not only appreciate but also can apply it." (Expert interviewee).

Participants were clear in making the point that the government should support the energy efficient products by enforcing legislations such as carbon emission tax and phasing out non-efficient products. Non-expert participants emphasized that by using LED in governmental buildings and public areas, they are promoting and improving the image and reputation of LEDs and this can certainly help lighting consumers to adopt the technology. The expert participants agree that NGOs should form to cut down greenhouse gas emissions.

In response to the question that what are the changes you suggest to have for lighting systems, the interviewees suggested that if the consumers are going to be encouraged to use new lights, these lights should save more energy (both in production and use procedure); and should be reliable in terms of color and brightness besides having less hazard.

"In terms of lights, they should use less electricity and no waste of energy and in their production and operation cycle has less harmful impression on environment, and also the recycling procedure should be easy and the parts can reuse after their end of life." (Expert interviewee).

"It should be energy efficient; costs should be justifiable and have an acceptable quality so not fail often during operation. It also should not be harmful for environment during using and after that." (Non-expert interviewee).

It is clear that non expert interviewees have a significant concern on the cost of the product and also the fact that these technologies are practical and not causing extra trouble.
Nevertheless both expert and non-expert interviewees are agreeing the fact that these new lamps must not be harmful to the environment. The expert interviewees more had a long term view on adopting these technologies. Their concern was the renewability of the products and the ability of them to be reused. TABLE II summarizes the findings for both expert and non-expert interviews.

TABLE II: SUMMARY OF INTERVIEWS

\begin{tabular}{|l|l|l|}
\hline Information Characteristics & Sources & Support \\
\hline & - Internet & \\
- Easy to understand & - Weblogs & $\bullet$ Policy \\
- Reliable & - Social & $\bullet$ Regulation \\
- Useful & network & $\bullet$ consumer \\
- Match everyday life & - NGOs & rebates \\
- New & technician & $\bullet$ subsidies \\
& - Advertisement & \\
& - Schools & \\
\hline
\end{tabular}

\section{CONCLUSION}

This article has highlighted the factors influencing energy efficient technology adoption among Malaysians by concentrating on LED lamps in lighting. This was done through interviews obtaining the viewpoint of both energy and environment experts and normal consumers. There were a series of questions studied coming up to important factors in Malaysian concept which, relate the content of information that are deliver to public as well as the forms that this information are delivered. During the interviews with participants a number of key questions were put forward; however one question which addressed the main body of this objective is how to integrate energy efficient technologies among Malaysian public? The response to this question was, including sustainability targets, government legislation and raising trust and support by government and NGOs. The information that consumer needs have to be new, useful and match their everyday life; this information should transfer to them by trustworthy sources. Another question is what is the reason behind adopting energy efficient technologies like LED lights? The participants were very clear with their responses stating money saving as the main driver following by environmental concern. Combining these findings together, it could be concluded that environmental knowledge and concern have significant impact on pro-environmental and green consumer behaviors.

\section{ACKNOWLEDGMENT}

The authors would like to thanks all those who participate in this study, including KOI Sdn Bhd, Focus Applied Technologies, Philips Lighting Malaysia and University Science Malaysia. We also would like to acknowledge Monash University Malaysia, Advanced Engineering Project, Sunway campus multidisciplinary platform for their supports.

\section{REFERENCES}

[1] IEA., World Energy Outlook 2011, 2011

[2] K. Ek and P. Söderholm, "The devil is in the details: Household electricity saving behavior and the role of information," Energy Policy, vol. 38 , pp. 1578-1587, 2010. 
[3] S. Caird et al., "Improving the energy performance of UK households: Results from surveys of consumer adoption and use of low- and zerocarbon technologies," Energy Efficiency, vol. 1, pp. 149-166.

[4] J. WatSon, "Setting priorities in energy innovation policy: Lessons for the UK," Energy Technology Innovation Policy, Harvard, Massachusetts, 2008.

[5] 9th Malaysia Plan 2006-2009, Malaysia Economic Planning Unit, Kuala lumpur, 2006

[6] Tenth Malaysia Plan 2011-2015, The Economic Planning Unit, Putrajaya, 2010.

[7] National Green Technology Policy Goals, Ministry of Energy, Green Technology and Water, Putrajaya, Malaysia, 2011.

[8] International Energy Agency. (2014). Malaysia Indicators. [Online]. Available:

http://www.iea.org/statistics/statisticssearch/report/?country=MALA YSIA\&product=indicators\&year=Select.

[9] Ministry of Energy Green Technology and Water. (2003). [Online]. Available: http://www.ktkm.gov.my/.

[10] P. Y. Gan et al, "A low carbon society outlook for Malaysia to 2035," Renewable and Sustainable Energy Reviews, vol. 21, pp. 432-443, 2013.

[11] The world Bank. (2014). Malaysia Indicators. [Online]. Available: http://data.worldbank.org/country/malaysia?display=default

[12] Lighting Market Characterisation, U.S. Department of Energy, Washington DC, 2012.

[13] R. Y. K. Chan, "Environmental attitudes and behavior of consumers in China," J. of Int. Consumer Marketing, vol. 11, pp. 25-52, 1999.

[14] J. B. M. Laroche and G. Barbaro-Forleo, "Targeting consumers who are willing to pay more for environmentally friendly products," Journal of Consumer Marketing, vol. 18, pp. 503-520, 2001.

[15] D. A. Amyx et al., "Influencers of purchase intentions for ecologically safe products: An exploratory study," in Proc. AMA Winter Educators Conference, Chicago, IL, 1994, pp. 341-347.

[16] T. Fleiter, S. Hirzel, and E. Worrell, "The characteristics of energy-efficiency measures - a neglected dimension," Energy Policy, vol. 51, pp. 502-513, 2012.

[17] S. T. Anderson and R. G. Newell, "Information programs for technology adoption: the case of energy-efficiency audits," Resource and Energy Economics, vol. 26, pp. 27-50, 2004.

[18] J. Corbin and A. Strauss, Basics of Qualitative Research: Techniques and Procedures for Developing Grounded Theory, Sage, 2008.

[19] A. Dobson, Sustainable Citizenship, Green House, London, 2011.

[20] E. Shove, "Converging conventions of comfort, cleanliness and convenience," Journal of Consumer Policy, vol. 26, pp. 395-418, 2003.

[21] M. P. Stavros et al., "Green marketing and Ajzen's theory of planned behaviour: A cross-market examination," Journal of Consumer Marketing, vol. 16, pp. 441-460, 1999.

[22] L. D. Cameron, P. M. Brown, and J. G. Chapman, "Social value orientations and decisions to take proenvironmental action," Journal of Applied Social Psychology, vol. 28, pp. 675-697, 1998.

[23] B. M. Bernstroem et al., "Electricity consumption and electricity saving in the Swedish households," Journal of Applied Socia Psychology, vol. 28, issue 8, pp. 675-697, April 1998.

[24] I. Knez, "Effects of colour of light on nonvisual psychological processes," Journal of Environmental Psychology, vol. 21, pp. 201-208, 2001.

[25] A. Kuijsters et al., "Improving the mood of elderly with coloured lighting," Constructing Ambient Intelligence, 2012, pp. 49-56.

[26] S. A. Samani, "The Influence of light on student's learning performance in learning environments: A knowledge internalization perspective," World Academy of Science, Engineering and Technology, vol. 81, 2011.

[27] D. Chapman and K. Sharma, "Environmental attitudes and behavior of primary and secondary students in Asian cities: An overview strategy for implementing an eco-schools programme," Environmentalist, vol. 21 , pp. 265-272, 2001.

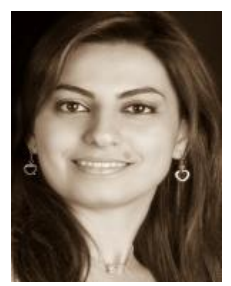

Hasti Khorasanizadeh is a PhD student in Discipline of Electrical and Computer Systems Engineering at Monash University Malaysia Campus. She received her BEng degree in software engineering (2004) from Sheikh Bahaee University in Isfahan-Iran and MSc degree in computer science majoring in management information systems (2010), from the University of Malaya (UM), Malaysia.

Her work experiences include a system analyzer in SDT Company, 2004-2006, and IT technician in Emco Iran consulting engineers 2010-2012. She also worked in Tehran Telecommunication Company for her internship. She joined Monash Malaysia as a PhD student in 2012, receiving a full scholarship and her research area is on LED lightening, effect of LED on human brain and educating the public to adopt LED in Malaysia. She published a conference article on web based system development for reflective learning improvement in e-Learning Asia Conference 2009 (eLAC09), Seoul-Korea. Mrs. Khorasanizadeh is a member of Institute of Electrical and Electronic Engineering (IEEE).

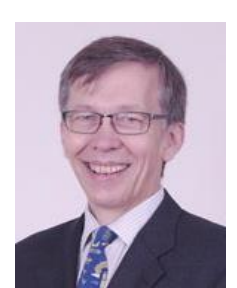

Jussi Parkkinen is a professor and the head of Discipline of Electrical and Computer Systems Engineering at the Monash University Malaysia. His research fields are spectral color and lighting science, especially using machine-learning methods. $\mathrm{He}$ received MSc degree in physics (1982) and $\mathrm{PhD}$ degree in mathematics (1989), from the University of Kuopio, Finland. In 1989-1990, he was a visiting researcher at the University of Iowa, IA; in 1990, he was a visiting professor at the University of Saskatchewan, Canada; in 1991-1992, he was the professor of computer science in the University of Kuopio, Finland; in 1992-1998, he was the professor of information processing; and in 1995-1998, dean of the Department of Information Technology at the Lappeenranta University of Technology, Finland. Since 1999, he has been a professor of computer science, in 1999-2005 the head of Department of Computer Science, in 2006-2007 the dean of Faculty of Science, and in 2007-2009 the vice rector (research) at the University of Joensuu, Finland. Since 2007, he has been a visiting professor at the Chiba University, Japan and since 2012 guest professor at the Tongji University, China. He has published over 70 scientific journals and numerous conference articles, mostly in the field of Color Science and Pattern Recognition.

Professor Jussi Parkkinen is a founding professor of the CIMET Erasmus Mundus MSc program, which combines color science and informatics. He is also a founding professor of IMPIT, an international MSc program and the CBU, Finnish-Russian Cross Border University MSc program in information technology. In 1995-1999, he was the chairman of the Finnish Pattern Recognition Society and he is a fellow of the International Association of Pattern Recognition (IAPR). He was the chairman of the CIE TC8-07 technical committee on Multispectral Imaging in 2004-2008. He has served as general chair and program chair in international conferences including CGIV 2008 and 2010.

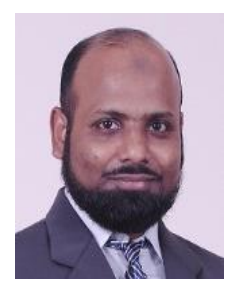

Rajendran Parthiban is an associate professor at the School of Engineering in Monash University Malaysia. He completed his bachelor of engineering with first class honours in 1997, and his PhD degree in optical networks in 2004 from the University of Melbourne, Australia.

He worked at Akbar Brothers Pvt. Ltd. (Sri Lanka) from 1998 to 2000 , where he computerized many of the company functions. In 2004, he joined the ARC Special Research Centre for Ultra-Broadband Information Networks (CUBIN) at the University of Melbourne. In CUBIN, he conducted research in developing new and cost-effective optical network architectures for carrying future Internet traffic. He joined as a lecturer at the School of Engineering in Monash University, Sunway Campus, Malaysia, in 2006. He served as the chair of Photonics, Semiconductor and Communications Technology Research Strength and the discipline head of the electrical and computer systems engineering from July 2009 to July 2010. He was appointed as the deputy head of the School in August 2010. He has experience in teaching five under graduate courses. His research interests are in optical networks, wireless sensor networks and visible light communications.

Dr. Parthiban is a member of Institute of Electrical and Electronic Engineering (IEEE), Institution of Engineering and Technology (IET) and Optical Society of America (OSA). He is also involved in the activities of Communications, Photonics and Education Societies of IEEE Malaysia Chapter. 